\title{
Centers for Population Health
}

National Cancer Institute

\section{Source}

National Cancer Institute. Centers for Population Health. NCI Thesaurus. Code C16178.

Centers for Population Health will be created to: 1) expand understanding of the social (e.g., income disparities, racial discrimination) and other causes of cancer-related health disparities, 2) develop new hypotheses for cancer control at social, institutional, and policy levels, and 3) develop, apply, evaluate, and disseminate interventions to improve population health. (from The NCI Strategic Plan to Reduce Health Disparities) 